\title{
Reseña de: Diálogo(s), epistemologia(s) e educação histórica: um primeiro olhar
}

\author{
Ana Isabel Ponce Gea
}

Cómo citar esta reseña: Ponce Gea, A. I. (2021). Reseña de: Diálogo(s), epistemologia(s) e educação histórica: um primeiro olhar. Revista de Ciencias Sociales Ambos Mundos, (2), 123-124. https://doi.org/10.14198/ambos.20785

\section{Autoría:}

Ana Isabel Ponce Gea

Universidad de Alicante, España

anaisabel.ponce@ua.es

https://orcid.org/0000-0003-0432-2595

\section{Resumen:}

Reseña de la publicación de Marques, L. A. y Gago, M. O. (coords.). (2021). Diálogo(s), epistemologia(s) e educação histórica: um primeiro olhar. Porto: CITCEM. 108 pp. ISBN 978-989-8970-31-2.

Fecha recepción: 30/08/2021

Fecha aceptación: 30/08/2021

Licencia: Este trabajo está sujeto a una licencia de Reconocimiento 4.0 Internacional de Creative Commons (CC BY 4.0).

https://creativecommons.org/licenses/by/4.0/

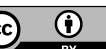

(c) Ana Isabel Ponce Gea, 2021

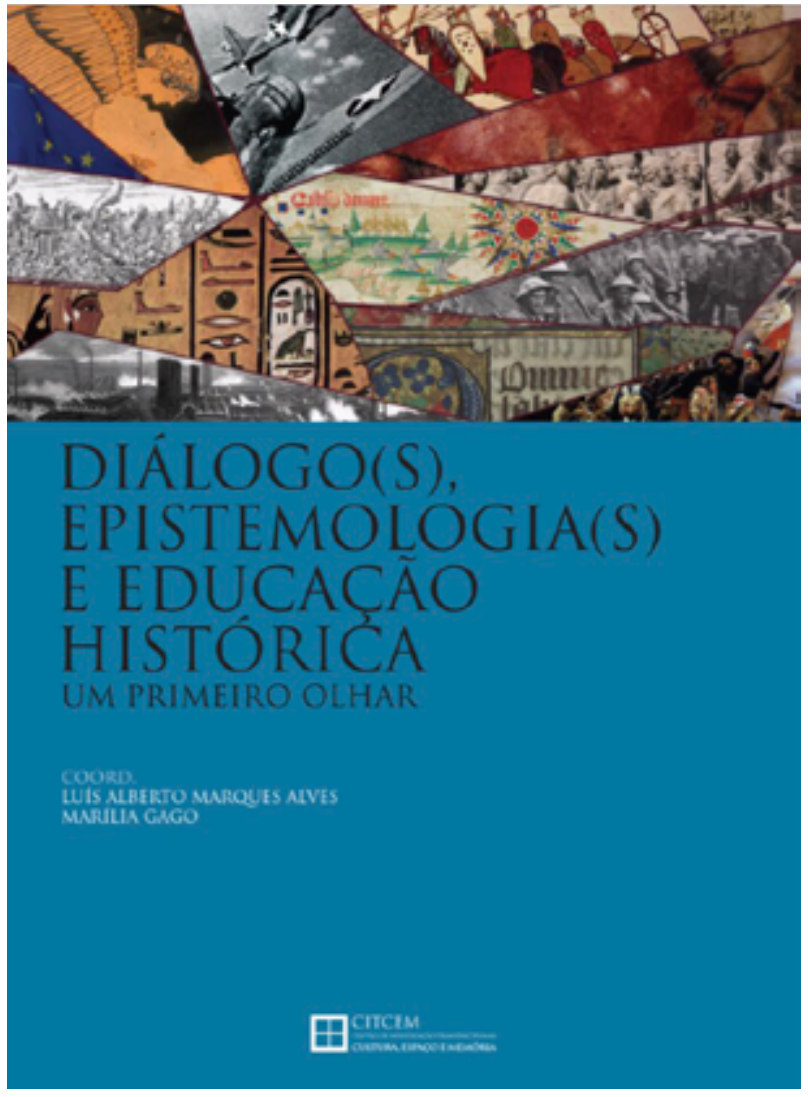

resultar "um primeiro olhar", una primera mirada, para aquellos que se acerquen al terreno de la enseñanza de la historia, siendo, para todos, una síntesis excepcional de lo que se viene haciendo y podría hacerse.

Abre la obra Jörn Rusen con el capítulo "Os principios da aprendizagem: a filosofía da história na didática da história", presentando las argumentaciones desde la filosofía como imprescindibles para una fundamentación de la didáctica de la historia. En el que seguramente pueda caracterizarse como el capítulo más generalista de la obra, plantea el autor tres preguntas sugerentes, que solo pueden responderse desde lo filosófico: qué es la historia, cuál es el proceso o el ámbito del aprendizaje histórico y por qué la historia debería estar presente 
en el currículo. Resume el autor en tres las formas de tematizar la didáctica de la historia: desde la filosofía material, como unidad de los acontecimientos del pasado; desde la filosofía formal, como forma de pensamiento histórico a través de la construcción de narrativas; y desde la filosofía funcional, como poder de la vida, que da sentido histórico al pasado según la orientación cultural del presente.

A la contribución de Rüsen, le sigue un trabajo de Arthur Chapman mucho más ligado a las situaciones específicas de enseñanza-aprendizaje: "Construindo a compreensão e o pensamento histórico através do ensino explícito de raciocínio histórico". Indaga el autor en la importancia del argumento histórico y la comprensión de la inferencia para el desarrollo del pensamiento histórico, con ejemplos prácticos y productos reales, que sirven como base para la reflexión sobre la creación y la evaluación de los argumentos. Así, el raciocinio que parte de la evidencia supone el avance desde el pensamiento novato, basado en el sentido común, a las ideas más sofisticadas propias del pensamiento histórico.

En el contexto brasileño, María Auxiliadora Schmidt, realiza un estudio de las relaciones entre la ciudadanía y las propuestas curriculares, ideas que recoge desde el título de su trabajo: "Cidadania e educação histórica: diálogos com documentos curriculares brasileiros". Partiendo de la separación que ha tenido lugar entre la didáctica de la historia y la historia académica, señala la autora cómo la enseñanza de la historia se ha alejado de lo propiamente histórico para acercarse a lo educativo. Concluye Schmidt que las relaciones entre la ciudadanía y lo curricular deben ser repensadas, pretendiendo una enseñanza de la historia que tenga como finalidad principal una comprensión humanista contemporánea. Para ello, se necesita una relación más orgánica entre cultura histórica y cultura escolar.

Este debate entre lo histórico y lo educativo está igualmente presente en el trabajo de Isabel Barca, "Educação histórica: desafios epistemológicos para o ensino e aprendizagem da história", tomando como ejes el pensamiento histórico y el pensamiento educativo. Comienza la autora reflexionando sobre el conocimiento sustantivo y estructural de la historia, haciendo una equivalencia con los conceptos más inmediatos y prácticos del pensamiento educativo y aquellos que pueden considerarse "de segundo orden". Así, tras ahondar en algunos conceptos de la epistemología de la historia (evidencia, explicación, narrativa y orientación temporal) y de la educación (en el marco constructivista), defiende Barca la necesidad de proporcionar a los jóvenes el análisis de varios argumentos, la confrontación de las versiones; alejadas, sin embargo, del relativismo total del "tudo vale" o "nada vale", bastante instaurado en lo educativo.

Precisamente, en el contraste de versiones, se fundamenta la práctica educativa que es base de la investigación "Os vídeos de histórica no Youtube como mobilizadores das evidencias audiovisuais na aprendizagem histórica dos jovens estudantes portugueses", de Marcelo Fronza. Con el objetivo de comprender cómo los jóvenes estudiantes generan sentido histórico a partir de evidencias audiovisuales, realiza el autor un estudio con participantes de entre 16 y 17 años, confrontando tres vídeos sobre la colonización europea de los pueblos de América. Los resultados ponen de manifiesto que, en efecto, los participantes proceden históricamente a la hora de tratar con las evidencias audiovisuales, animando al lector a la utilización de estos recursos como fuente histórica.

Cierra la obra el capítulo "Ideias de jovens sobre mudança e sua relação com o novo humanismo" de Lucas Pydd Nechi. Se parte de la consideración del concepto de cambio como fundamental en el desarrollo de la conciencia histórica. A partir de ello, se realiza un estudio con 40 jóvenes brasileños, de Curitiba, y 38 jóvenes londinenses, estudiando la idea de cambio en torno a cuestiones como la dignidad humana, la dignidad de grupos (mujeres, homosexuales, ...) o la relación con la naturaleza. En síntesis, los estudiantes ingleses ven una mayor mejoría que los brasileños en el modo de vida, lo que pone de manifiesto la influencia del contexto en la concepción sobre el cambio.

Los autores nos ofrecen, entonces, una variedad de reflexiones propias de su campo específico de estudio, merecedoras de leer con detenimiento y pensar en conjunto. La obra nos entrega a los lectores ideas y recursos, pero, sobre todo, nos da una oportunidad para el detenimiento y el pensamiento. Como señala el profesor Alves, en una traducción propia, "todos, con sus perspectivas y visiones sustentadas, nos incomodan, nos provocan, nos obligan a reflexionar sobre lo que hemos estado haciendo en nuestros espacios académicos o investigativos, apuntando claramente caminos de una Epistemología y Educación Histórica que solo puede ser construida en el Diálogo(s)" (p. 106).

Es recomendable su lectura pausada. A cualquier investigador le sugerirá, sin duda, un diálogo, también, con sus propios trabajos y pensamientos. 